\title{
Powertrain dynamics and control of a two speed dual clutch transmission for electric vehicles
}

Paul Walker ${ }^{\mathrm{a}}$, Bo Zhu $^{\mathrm{a}}$, Nong Zhang ${ }^{\mathrm{a}}$

a School of Electrical, Mechanical, and Mechatronic Systems, Faculty of Engineering and Information Technology, University of Technology Sydney, Australia, 15 Broadway, Ultimo, NSW Australia 2007

*Corresponding author details: Email: Paul.Walker@uts.edu.au Phone: +61 295142412 Fax: +61295142567

Postal address: University of Technology Sydney; P.O. Box 123; Broadway, NSW, Australia 2007

\begin{abstract}
The purpose of this paper is to demonstrate the application of torque based powertrain control for multi-speed power shifting capable electric vehicles. To achieve this goal it presents a detailed simulation and experimental investigation of the transient behavior of a dual clutch transmission equipped multi-speed electric vehicle powertrain during a combination of power-on and power-off up and down shifts. A system model is developed that integrates a DC equivalent motor model, hydraulic control system and multi-body powertrain model for virtual prototyping of the integral system. Control strategies for power-on and power-off up and down shifts are then presented, and detailed simulations of the transient behavior of the powertrain system model are conducted for each of the four shift cases. These results are then experimentally verified on a powertrain test rig, purpose built for the study of transmission control. Shift duration and vehicle jerk are used as metrics to demonstrate that the presented strategies are effective for shift control in electric vehicles.
\end{abstract}

Keywords: Electric vehicle, powertrain, dual clutch transmission, shift control 


\section{Introduction}

As the electric vehicle (EV) market continues to grow, new strategies for improving both the dynamic performance and overall economy of the vehicle develop at pace. Several recent studies [1-3] have developed the concept of multispeed electric vehicle platforms as serving the need for both a wider range of torque application and higher energy efficiencies than single speed equivalents. Such investigations have typically focused on the system level perspective to evaluate the economy and performance improvements, but have not included detailed study of the controllability of these platforms during gear shift. The purpose of this paper is to fill that gap in knowledge and evaluate the transient behavior of multi-speed EVs (MSEV) during gear shift. This includes all forms of shifting, power-on and power-off up and down shifts, with comprehensive experimental verification of results.

Applications for DCTs have traditionally been orientated around conventional vehicle systems. However, as hybrid and electric vehicle systems have come to the fore DCTs have been viewed as an applicable to these vehicle architectures. Primarily as multiple speed ratios and power-on shifting capabilities meet requirements for both efficiency and driver comfort [4]. Recent examples of the application of these transmissions include clutchless automated manual transmissions (CLAMT) [5], dual motor multispeed EV transmissions [6], and two speed planetary transmission [7]. Each configuration has both benefits and limitations. For example, the CLAMT configuration is simple to control and will have high operating efficiencies with fewer viscously coupled components (i.e. open wet clutches). However, torque interrupt is present during gear change events as the motor must be de-energized to facilitate the release of synchronizer mechanisms during gear change. Alternatively, dual motor EV platforms overcome this limitation through toque hole filling with the second motor, but incur additional costs with multiple motors and power electronics. Dual clutch transmission (DCT) and AT variants of MSEVs overcome this limitation through the use of clutch-to-clutch shift control strategies, as has been demonstrated in conventional DCT and AT studies such as[8,9]. 
The remainder of this paper is divided as follows. Section 2 presents the detailed mathematical modeling of the powertrain system, including electric machine and power electronics model, simplified clutch hydraulics model, and vehicle powertrain model. Section 3 details the powertrain control strategy employed, including power-on and power-off up and down shift strategies. Section 4 presents several measures of shift quality that are utilised in the study for evaluating performance. Section 5 presents the simulation and experimental results of the study. Finally, conclusions and recommendations are presented in Section 6.

\section{Prototype development and evaluation of appropriate gear ratios}

Much work has been involved in the study of gear ratio selection for multi-speed EVs, including work in the development of an inverse automated manual transmission (IAMT) [10], where a dynamic programming strategy was applied to select the optimal ratios. A study by Zhou, et al, [11] mapped the driving efficiency over a large number of gear ratios using simulations for the NEDC driving cycle. This demonstrates that there are a large number of ratio combinations that will provide very similar average driving efficiency. However, transmission efficiency was considered to be constant. In Di Niola, et al, [12] it was proposed that the use of multispeed transmissions can reduce peak motor torque demands, this was supported by work in Roser [13].

For the purpose of prototyping of this system a DQ250 dual clutch transmission with hydraulically actuated wet clutches was selected, primarily as the system is robust and the wet clutches are more resilient during testing. The downside to the use of a wet clutch DCT is that there are higher parasitic losses in the hydraulic control system and wet clutch, which is undesirable for EV applications. Using this transmission with parallel lay shafts, gear ratios were restricted to $3.46,2.08,1.32$, and 0.9 with a final drive of 4.12, and 0.91 and 0.79 with a final drive of 3.04. Based on the result of studies in Zhou, et al, [11] and Roser, et al, [13] ratios of 2.08 and 1.32 (both multiplied by the final drive ratio of 4.12 to give 8.5696 and 5.4384 , respectively) were selected to minimise the step down in speed during 
shifting, whilst maintaining a reasonable ratio spread. This will also have the effect of reducing the losses in the wet clutches as these losses are dependent on the relative speed in the clutch.

\section{Mathematical modelling of the powertrain}

Schematically, the powertrain under test in this investigation is shown in Figure 1, this includes the main power electronics to control motor speed and torque, the motor itself, DCT equipped powertrain, and hydraulic control unit for the transmission (i.e. the major components that are this study comprises of). Batteries are excluded in this case as the experimental powertrain is driven of three phase mains power (not shown) using an AC/DC drive. More details on this experimental setup are presented in Section 5. In this section the modeling techniques used in this study are detailed for the development of the system model.

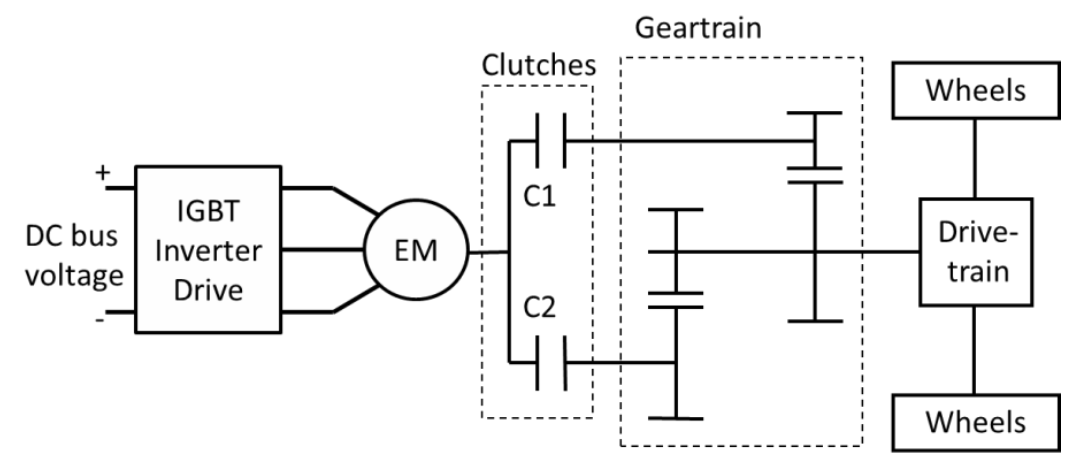

Figure 1: Electric vehicle powertrain schematic

\subsection{Electric machine modeling}

Mathematical models of electric machines are well established, the basic dynamics can be captured using equivalent circuit models, as has been performed in [14]. For a three phase permanent magnet DC motor/generator with surface mounted magnets (referred to as EM in Figure 1) the formulation is used to develop a relationship between electrical input and the mechanical output of the motor. For many studies this is then controlled using a DC voltage input. The equivalent DC circuit model is shown below for the electric machine. This model is integrated with the powertrain model, as detailed in section 3.3.

The differential equation for the electric circuit is defined as: 
$L I_{E M}^{\dot{ }}=K_{e} \dot{\theta_{1}}-R I_{E M}+V$

where $I_{E M}$ is the line current, $L$ is the line inductance, $K_{e}$ is the back emf constant, $R$ is the line resistance, and $\mathrm{V}$ is line voltage.

The electromagnetic torque produced in the EM is defined as follows:

$T_{E M}=K_{T} I_{E M}$

where $\mathrm{K}_{\mathrm{T}}$ is the torque constant and $\mathrm{T}_{\mathrm{EM}}$ is the electromagnetic torque. These two equations represent the electrical component of the model and are coupled with the remainder of the powertrain model below.

The power electronics driving the electric machine is an insulated gate bipolar transistor (IGBT) based inverter. Papers such as [15] demonstrate the modelling of such a system to be fairly intricate, and are beyond the scope of this paper. Additionally, any time delay present in the inverter/controller is well below that of the mechanical systems. Thus, to capture this characteristic the inverter/controller it is therefore treated as a simple time delay, shown in the block diagram in Figure

2. This captures the main characteristics of the drive that will influence control without over complicating the system model.

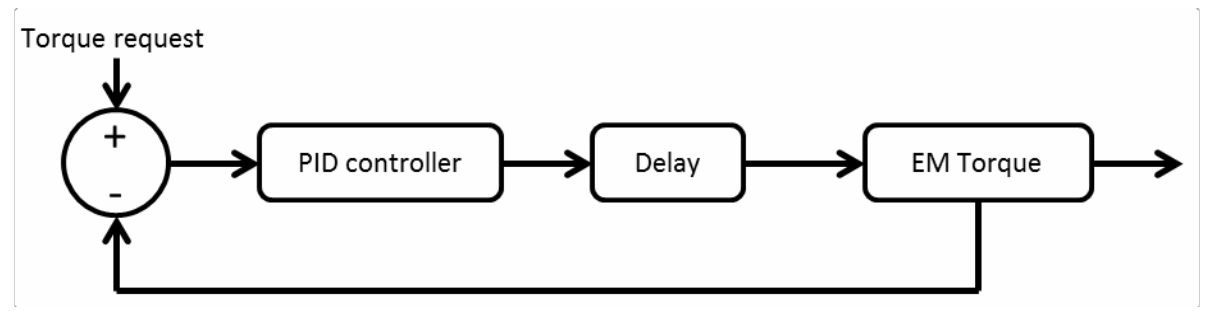

Figure 2: Simplified model of the Inverter/controller

\subsection{Clutch modelling}

In previous [8] and more recent works [16] mathematical models of the main DCT hydraulics component, the direct acting clutch control solenoid, have been established and experimentally verified. The same model is implemented as part of the complete powertrain system in this study to provide accurate replication of the clutch system dynamics. Extensive details for the clutch modelling and its verification can be found in [16]. 
The piecewise clutch model is based on $[8,9]$, where three operating states for each of the two clutches are available according to fundamental friction relationships. Mathematically this is described in equations $3-6$, if there is a load on the clutch with a relative speed between plates the clutch torque is defined by line 1 of equation 3 . Once the relative speed is reduced to zero, clutch torque reverts to the estimated average torque in the clutch, see equation 4 . This is limited by the static friction torque in the transmission. These equations are applicable to clutch one and clutch two, note that parameters are summarised in Appendix A.

$$
\begin{aligned}
& T_{C}=\left\{\begin{array}{cc}
\operatorname{sign}(\Delta \dot{\theta}) n \mu_{D} R_{m} F & \Delta \dot{\theta} \neq 0 \\
\operatorname{sign}(\Delta \dot{\theta}) n \mu_{S} R_{m} F & \Delta \dot{\theta}=0,\left|T_{A V G}\right| \geq\left|n \mu_{S} R_{m} F\right| \\
T_{A V G} & \Delta \dot{\theta}=0,\left|T_{A V G}\right|<\left|n \mu_{S} R_{m} F\right|
\end{array}\right. \\
& T_{A V G}=\frac{T_{C 1 a}+T_{C 1 b}}{2} \\
& T_{C 1 a}=-J_{2} \ddot{\theta}_{2}+K_{1}\left(\theta_{1}-\theta_{2}\right)-T_{C 2} \\
& T_{C 1 b}=J_{3} \ddot{\theta}_{3}+K_{2}\left(\theta_{3}-\gamma_{1} \theta_{4 B}\right)
\end{aligned}
$$

where $n$ is the number of friction surfaces, $\mu_{s}$ is the static friction coefficient, $\mu \mathrm{i}$ is the dynamic friction coefficient, $\mathrm{Rm}$ is the mean clutch diameter, and $\mathrm{F}$ is the normal force, calculated from the piston surface area multiplied by clutch pressure.

\subsection{Powertrain modelling}

The electric vehicle (EV) powertrain that is the subject of this investigation is based on a front wheel drive vehicle platform. The main variation from conventional vehicle platforms is the electric motor and flywheel. For the EV powertrain the flywheel and associated torsional damper is removed completely. The reduces the rotating inertia to minimise the duration of gear shift, and is acceptable as the engine torque harmonics present with an internal combustion engine are no longer present.

Powertrain modelling follows traditional methods such as $[9,17,18]$ with the major powertrain 
components modelled as lumped inertia elements connected with corresponding stiffness and damping components. The electric vehicle is modelled as a front wheel drive equivalent powertrain comprising of motor, clutch assembly, two speed transmission, differential and wheels. The main elements of the powertrain are presented in Figure 3. This is a lumped mass representation of a torsional powertrain system and will be used to build an equivalent powertrain model for simulations and control of the system. A number of simplifying assumptions are made to reduce model complexity:

1. Tyre equivalent stiffness and damping is linear

2. There is no backlash in meshing gears

3. The differential assembly can be reduced to an inertia and half shafts

4. A DC circuit equivalent model of the motor is sufficient for simulations.

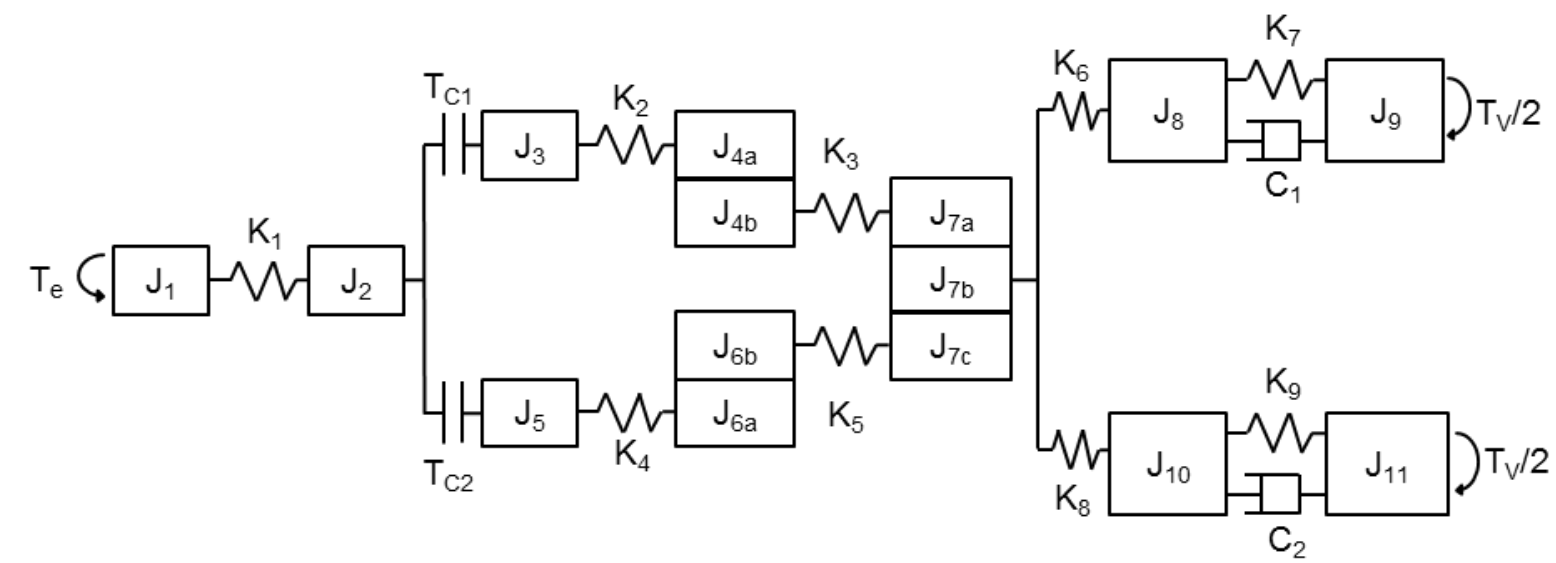

Figure 3: Lumped powertrain model schematic for a front wheel drive EV

The powertrain equations of motion are derived using Newtonian mechanics, and parameters are summarised in Appendix A. These equations of motion can be arranged in a similar manner to [17] to represent the powertrain model with either clutch one or clutch two engaged, but, unlike [17], with only two gears there is no requirement for synchronisers.

$$
\begin{aligned}
& J_{1} \ddot{\theta}_{1}=T_{E M}-K_{1}\left(\theta_{1}-\theta_{2}\right) \\
& J_{2} \ddot{\theta}_{2}=K_{1}\left(\theta_{1}-\theta_{2}\right)-T_{C 1}-T_{C 2} \\
& J_{3} \ddot{\theta}_{3}=T_{C 1}-K_{2}\left(\theta_{3}-\gamma_{1} \theta_{4 B}\right) \\
& \left(\gamma_{1}^{2} J_{4 A}+J_{4 B}\right) \ddot{\theta}_{4 B}=\gamma_{1} K_{2}\left(\theta_{3}-\gamma_{1} \theta_{4 B}\right)-K_{3}\left(\theta_{4 B}-\gamma_{3} \theta_{7 B}\right)
\end{aligned}
$$




$$
\begin{aligned}
& J_{5} \ddot{\theta}_{5}=T_{C 2}-K_{4}\left(\theta_{5}-\gamma_{2} \theta_{6 B}\right) \\
& \left(\gamma_{2}^{2} J_{6 A}+J_{6 B}\right) \ddot{\theta}_{6 B}=\gamma_{2} K_{4}\left(\theta_{5}-\gamma_{2} \theta_{6 B}\right)-K_{5}\left(\theta_{6 B}-\gamma_{4} \theta_{7 B}\right) \\
& \left(J_{7 B}+\gamma_{3}^{2} J_{7 A}+\gamma_{4}^{2} J_{7 C}\right) \ddot{\theta}_{7 B}= \\
& \gamma_{3} K_{3}\left(\theta_{4 B}-\gamma_{3} \theta_{7 B}\right)+\gamma_{4} K_{5}\left(\theta_{6 B}-\gamma_{4} \theta_{7 B}\right)-K_{6}\left(\theta_{7 B}-\theta_{8}\right)-K_{8}\left(\theta_{7 B}-\theta_{10}\right) \\
& J_{8} \ddot{\theta}_{8}=K_{6}\left(\theta_{7 B}-\theta_{8}\right)-K_{7}\left(\theta_{8}-\theta_{9}\right)-C_{1}\left(\dot{\theta}_{8}-\dot{\theta}_{9}\right) \\
& J_{9} \ddot{\theta}_{9}=K_{7}\left(\theta_{8}-\theta_{9}\right)+C_{1}\left(\dot{\theta}_{8}-\dot{\theta}_{9}\right)-T_{V} / 2 \\
& J_{10} \ddot{\theta}_{10}=K_{8}\left(\theta_{7 B}-\theta_{10}\right)-K_{9}\left(\theta_{10}-\theta_{11}\right)-C_{2}\left(\dot{\theta}_{10}-\dot{\theta}_{11}\right) \\
& J_{11} \ddot{\theta}_{11}=K_{9}\left(\theta_{10}-\theta_{11}\right)+C_{2}\left(\dot{\theta}_{10}-\dot{\theta}_{11}\right)-T_{V} / 2
\end{aligned}
$$

To summarise powertrain elements: Inertia elements represented by $\mathrm{J}_{1}, \mathrm{~J} 2, \mathrm{~J} 3, \mathrm{~J} 4 \mathrm{a}$ and $\mathrm{J} 4 \mathrm{~b}, \mathrm{~J} 5, \mathrm{~J} 6 \mathrm{a}$ and $\mathrm{J} 6 \mathrm{~b}, \mathrm{~J} 7 \mathrm{a}$ and $\mathrm{J} 7 \mathrm{~b}$ and $\mathrm{J} 7 \mathrm{c}, \mathrm{J} 8, \mathrm{~J} 9, \mathrm{~J} 10, \mathrm{~J} 11$ are the electric machine, flywheel/Clutch drum, clutch pack 1 , reduction gear pair 1 , clutch pack 2, reduction gear pair 2, final drive set, wheel hub 1 , half vehicle, wheel hub 2 , and half vehicle, with $\theta$ and corresponding time derivatives used to represent the angular displacement, velocity, and acceleration for corresponding powertrain elements. Stiffness elements are represented as $\mathrm{K} 1, \mathrm{~K} 2, \mathrm{~K} 3, \mathrm{~K} 4, \mathrm{~K} 5, \mathrm{~K} 6, \mathrm{~K} 7, \mathrm{~K} 8$, and $\mathrm{K} 9$ as the motor output Shaft, primary shaft 1 , lay shaft 1 , primary shaft 2 , lay shaft 2 , half shaft 1 , half shaft 2 , tyre 1 and tyre 2 stiffness, respectively. Damping is represented withC1 for the motor, C2 for the transmission, C3 for tyre 1 and $C_{4}$ for tyre 2. Gear ratios are represented as $\nu_{1}, \nu_{2}$ for the transmission reduction pairs, and $\gamma 3, \gamma 4$ for final drive pairs.

The vehicle resistance torque is the combination of rolling resistance force, incline load and air drag. It is defined as:

$$
T_{v}=\left(C_{R} m_{V} g \cos \beta+m_{V} g \sin \beta+0.5 C_{D} \rho A_{V} \omega_{V}^{2} r_{T}^{2}\right) \times r_{T}
$$

where $C_{R}$ is rolling resistance coefficient, $g$ is gravity, $\theta$ is incline angle $C_{D}$ is drag coefficient, $\rho$ is air density, and $A_{V}$ is the vehicle frontal area, with parameters defined in Appendix $A$.

\section{Powertrain control}

Power train control is achieved in a hierarchical manner, see Figure 4. The vehicle control unit (VCU) 
coordinates normal driving of the vehicle as well as gear shifting. During normal operation the gear ratio is fixed and minimal effort is required in the transmission control unit (TCU), however as driver inputs change so does the required motor torque and the motor control unit (MCU) controls the power inverter to meet torque demands. Alternatively, during gear change much higher demand is placed on the TCU and coordination between motor and transmission is handled by the VCU. In the case of this study the VCU will monitor the vehicle speed and torque, determining the requirements for gear change based on this information.

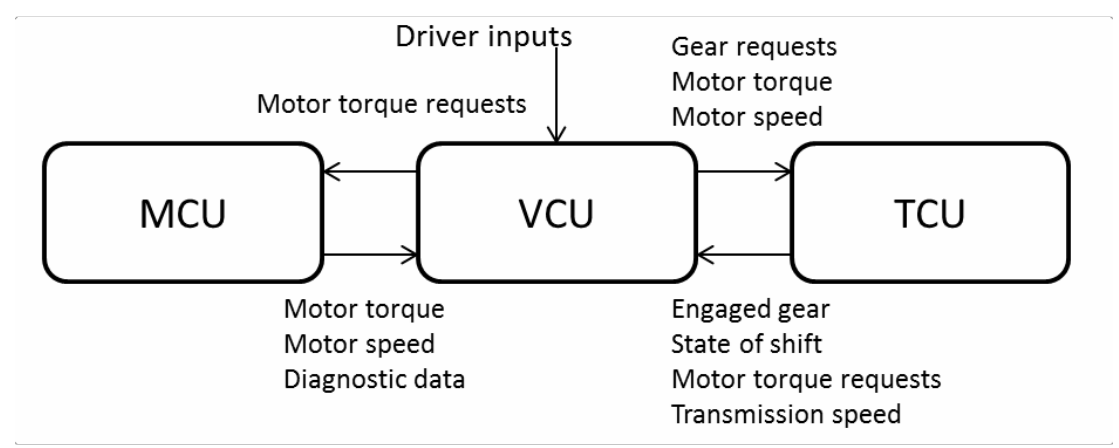

Figure 4: Vehicle control hierarchy

\subsection{Control Hierarchy}

\subsubsection{Vehicle control unit}

Experimentally, powertrain control is achieved using MicroAutoBox II. In terms of control hierarchy it is split into two levels. The top level control is for overall vehicle control using the VCU. This takes inputs from a number of sensors and controllers, determines driving state and sends additional commands to both the MCU and TCU. The VCU takes input data from the electric motor, such as motor torque and speed, transmission, such as clutch pressure and transmission speed, and input commands from the driver, i.e. throttle or driving cycle data, and uses this information to determine the driving state of the vehicle and deliver driving demands to the motor and transmission. This includes both torque commands and braking for the motor and gear selection and pump pressure for the transmission.

\subsubsection{Motor control unit}

There are two separate considerations required for the establishment of motor control, those during 
normal operation and those during shifting. During normal driving accelerator and brake requests are converted to demand torques for the motor and load is applied to drive the vehicle, or regenerative braking is initiated. However, during gear change, the torque demands from the VCU are overridden by the TCU so that the inertia phase can be properly executed through the reduction in output motor torque. As identified in Figure 1, the motor controller is an IGBT inverter that converts the $\mathrm{DC}$ bus voltage to a three phase voltage input to the motor. In this study both normal operation and shift control utilise torque based motor control for the electric motor.

\subsubsection{Transmission control unit}

Transmission control handles the shifting requirements during gear change. The TCU essentially takes control of the vehicle during shifting as it must control both the electric motor and clutch hydraulics during shifting to ensure a high quality gear change is achieved. It controls solenoid valve pressures and sends overriding torque commands to the electric motor during shifting. Specific details for the clutch-to-clutch shift control requirements are detailed in the following section.

\subsection{Clutch-to-clutch shift control strategies}

For the prototype two speed DCT in this study synchroniser mechanisms are not required, simplifying the mechatronics required for gear changing, reducing cost and complexity of the transmission. Additionally, without the need for friction launching of the vehicle, this component of transmission control is eliminated. The main consideration for DCT shifting will therefore be only the coordination of clutch-to-clutch shifting control. In the process of shifting, one clutch disengaged and another engaged. For the strongly nonlinear behaviour of clutch friction, i.e. speed and temperature dependencies during the process of shifting, and with the torque coupling in the torque transfer, it is a complex process to accurately calculate the transfer torque [19]. Furthermore with the hysteresis and nonlinear behaviour of the hydraulic system [16] increases the complexity in such estimations. Strategies to control the shifting process become the key technology, with the ultimate objective of balancing both the shifting time and comfort. 
There are several control methods that have been applied to dual clutch transmissions, ranging from basic open loop methods through to fuzzy control techniques. A basic method applied by Goetz [20] and also Zhang, et al, [21] and Kulkarni, Shim and Zhang [22] is to use a controlled signal to perform the shift. Goetz [20] demonstrates both speed and torque control techniques, while Zhang [21] and Kulkarni [22] adopt pressure profiles to perform the shift. In this way it is somewhat similar to speed based control techniques for automatic transmissions.

Open loop control methods have be adopted by Song [23] for heavy vehicle applications. There is demonstrative success for the capability to perform shifts, and results have similar comparison to a single clutch transmission. The simulations demonstrate that there is no speed loss during the shift from the DCT. However, there are still significant improvements that can be made to the shift responses to improve the engagement, noting particularly the interruption of vehicle speed during shifts. Wu, et al, [24] makes use of feedback linearization to reduce power-train complexity and applied PID control to the resulting model with some success. Analysis of the clutch force by Liu, et $a l,[25]$ enabled improvement of shift quality, while [26] uses the applied force as a measure of shift quality, combining clutch and engine as control variables.

Transmission shifting can be generally divided into power-on gearshift and power-off gearshift, in which power-on gearshift takes place whilst the motor drives the wheel, and power-off gearshift takes place whist there is no load from the motor driving the wheels. This paper will present shift control techniques for up and down shifts using both power-on and power-off driving conditions. The four alternative shifting strategies are presented in Figure 5. These are discussed in greater detail in the following sections as the control algorithms are presented. 

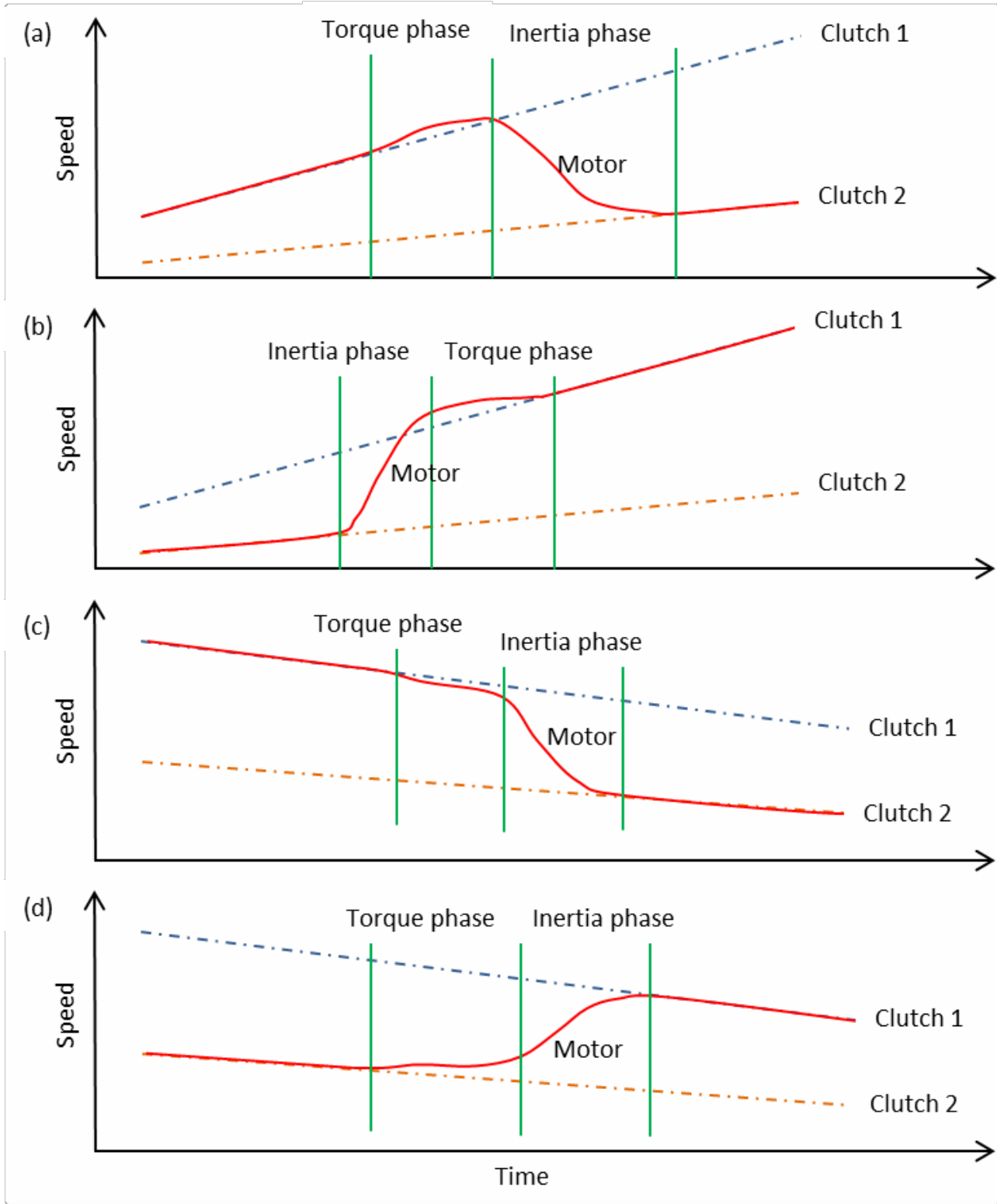

Figure 5: Power-on and power-off shift control strategies, (a) Power-on upshift, (b) power-on downshift, (c) power-off upshift, and (d) power-off downshift.

\subsubsection{Power-on upshift}

The process for power-on upshifting is shown in Figure 6. After the process is initialised clutch 1 pressure is reduced to the slip pressure and clutch 2 is prefilled. After a short time delay, torque transfer begins with clutch 1 slip compensation control. The purpose of this is to control clutch 1 slip within a proscribed margin to ensure minimal transients results in the output torque during torque 
handover. The slip value recommend in literature [20] is 5rpm, as it is impossible to control the slip in a constant value, an intermittent zone of $8-12 \mathrm{rpm}$ is selected.

When clutch 1 pressure decreases down to zero, the torque phase is completed and inertia phase begins. A number of papers $[18,20]$ recommend speed closed loop control in this phase, make the engine speed to follow a given speed profile. In this paper a simple sectional torque control algorithm is studied. The process of speed synchronization is divided into three sections. In the first stage the motor torque is reduced gradually. In the second section motor torque is held at the desired target value. Finally, the third stage is when motor torque begins to increase to its initial value. Through numerical simulations these ramp rates and torque limits can be calibrated to obtain suitable balance between duration of shift and any vehicle jerk. When motor speed synchronizes with clutch 2 , its pressure is increased to line pressure and motor torque control is returned to the driver. The shifting process is then considered to be complete.

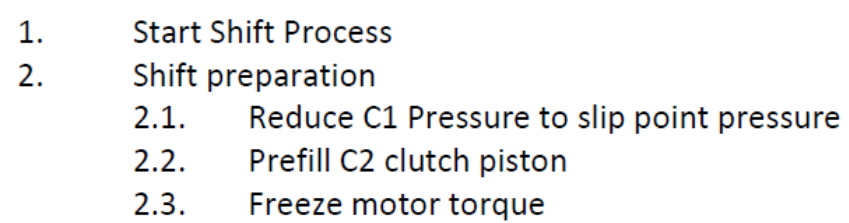

Figure 6: Control algorithm of Power-on Up-shift 


\subsubsection{Power-on downshift}

The process for Power-on down-shifting is reverse to power-on upshifts; it is begin with inertia phase. As shown in Figure 7, the first step is to reduce clutch 2 pressure and pre-fill clutch 1 pressure for preparation of initiating slip of clutch 2. For down shifting from 2 nd gear to 1 st gear, the speed of motor will increase to synchronize the clutch 1 speed, therefore a negative friction torque will be observed if the torque phase is initiated first. Consequently, during the inertia phase Clutch 2 is allowed to slip and the motor torque is used to accelerate the friction plates to above the Clutch 1 speeds. Thus a positive friction torque will be observed during the torque phase as torque handover occurs. When the motor speed has achieved a speed greater than the clutch 1 speed, inertia phase finishes and torque phase starts.

In the torque phase, reduce clutch 2 pressure and meantime ramp up clutch 1 pressure, also the same slip feedback compensation control as in power-on up-shift control is adopted here, to control clutch 1 slip value in the given value during torque transfer to get a smooth shifting. While clutch 2 pressure is down to zero, increase clutch 1 pressure to line pressure and recover motor torque to driver request value, the whole shifting process is complete. 


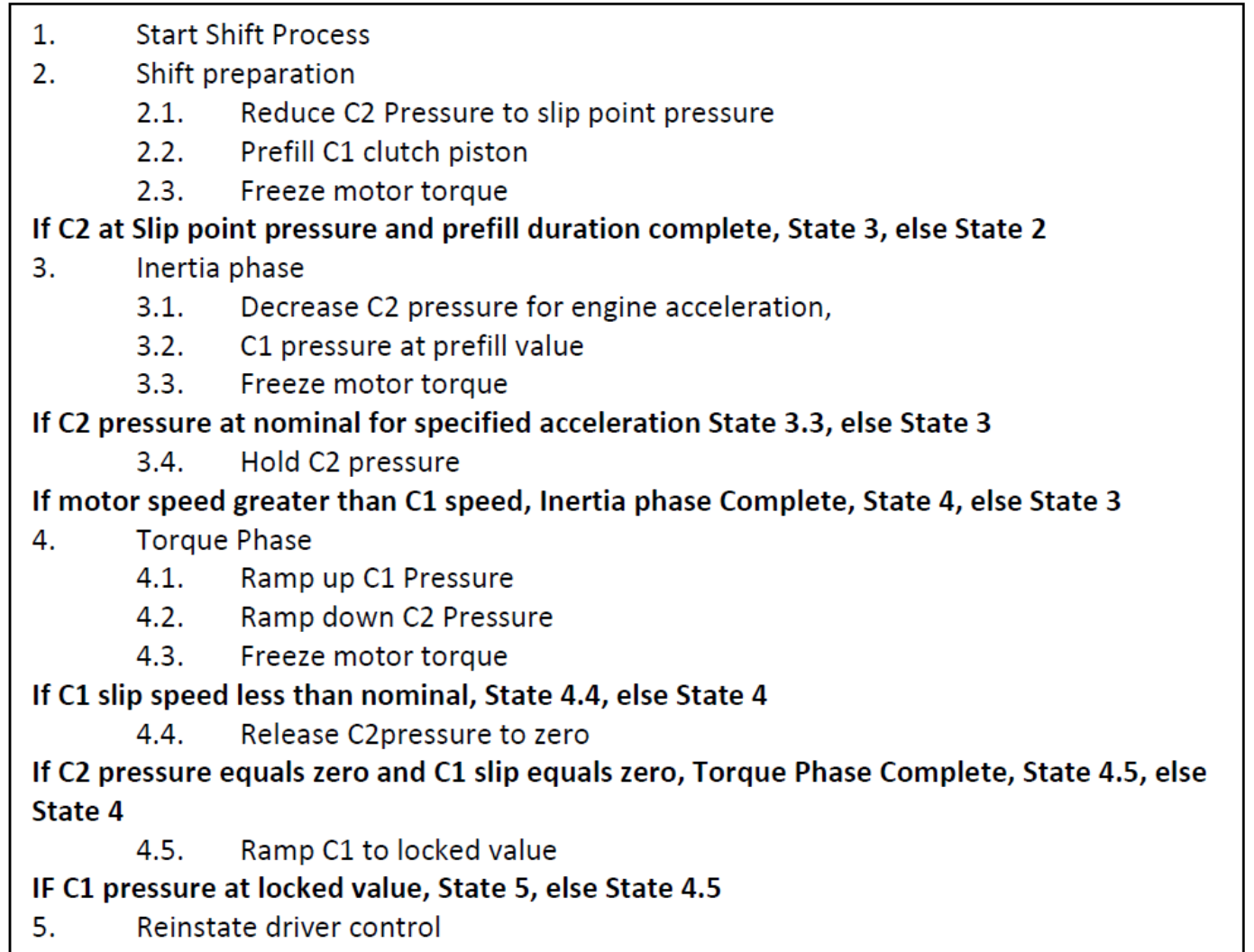

\section{Figure 7: Control algorithm of Power-on Down-shift}

4.2.3. Power-off upshift

The process for power-off upshifting is much simpler than the equivalent power-on shift. Primarily this is because there is no power transfer in the forward direction, and the drag torque of the motor is much smaller than an equivalent combustion engine. There will be no obvious torque interruption during the shifting, so the requirements for control are decreased. Power-off upshifting requires the release of the engaged clutch (i.e. Clutch 1) through reduction in the pressure to enable clutch slip. Clutch 2, the oncoming clutch, pressure is then ramped up to let the clutch friction to reduce the clutch slip speed to zero.

As presented in the control algorithm in Figure 8, at the beginning of Power-Off Up-Shift, clutch 1 pressure was reduced and clutch 2 is prefilled. This is followed by speed synchronisation. The process of speed synchronization is divided into two sections, the first section is defined here as the torque phase, here $\mathrm{C} 1$ clutch pressure is reduced to release engaged clutch, and completes with a zero C1 pressure. This is followed by the inertia phase, here the $\mathrm{C} 2$ pressure is ramped up as friction torque is used to synchroniser the ongoing clutch plates. The inertia phase finishes with the lockup of clutch 
2 , and the shift is complete. During the entire shift process, motor torque unchanged near or at a nominal torque of zero.

In the torque phase, torque transfer begins with clutch 1 slip compensation control. The purpose of this is to control clutch 1 slip at a given value to guarantee output torque without generating transient shock. This control is the same as Power-On Up-Shift control. When clutch 1 pressure decreases down to zero, then increase clutch 2 pressure to line pressure, the torque phase finishes.

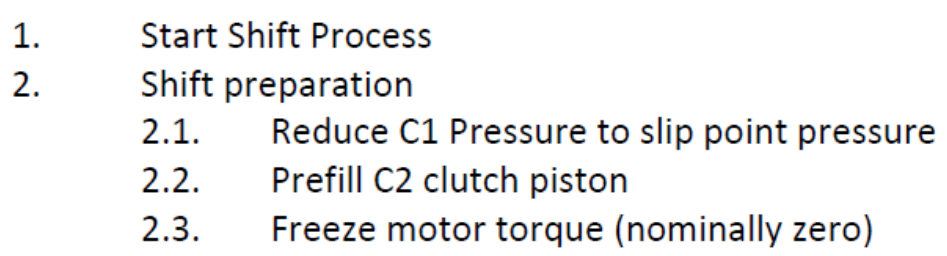

Figure 8: Control algorithm of Power-Off Up-Shift

\subsubsection{Power-off downshift}

The shifting control of Power-off Down-shift is much the same as Power-On Up-Shift, first torque phase and then inertia phase. Again as there is no requirement for torque transfer during the shift process and with zero motor torque the shift control strategy must rely of ongoing clutch friction to complete the required speed change. Detailed control algorithms are in Figure 9. 


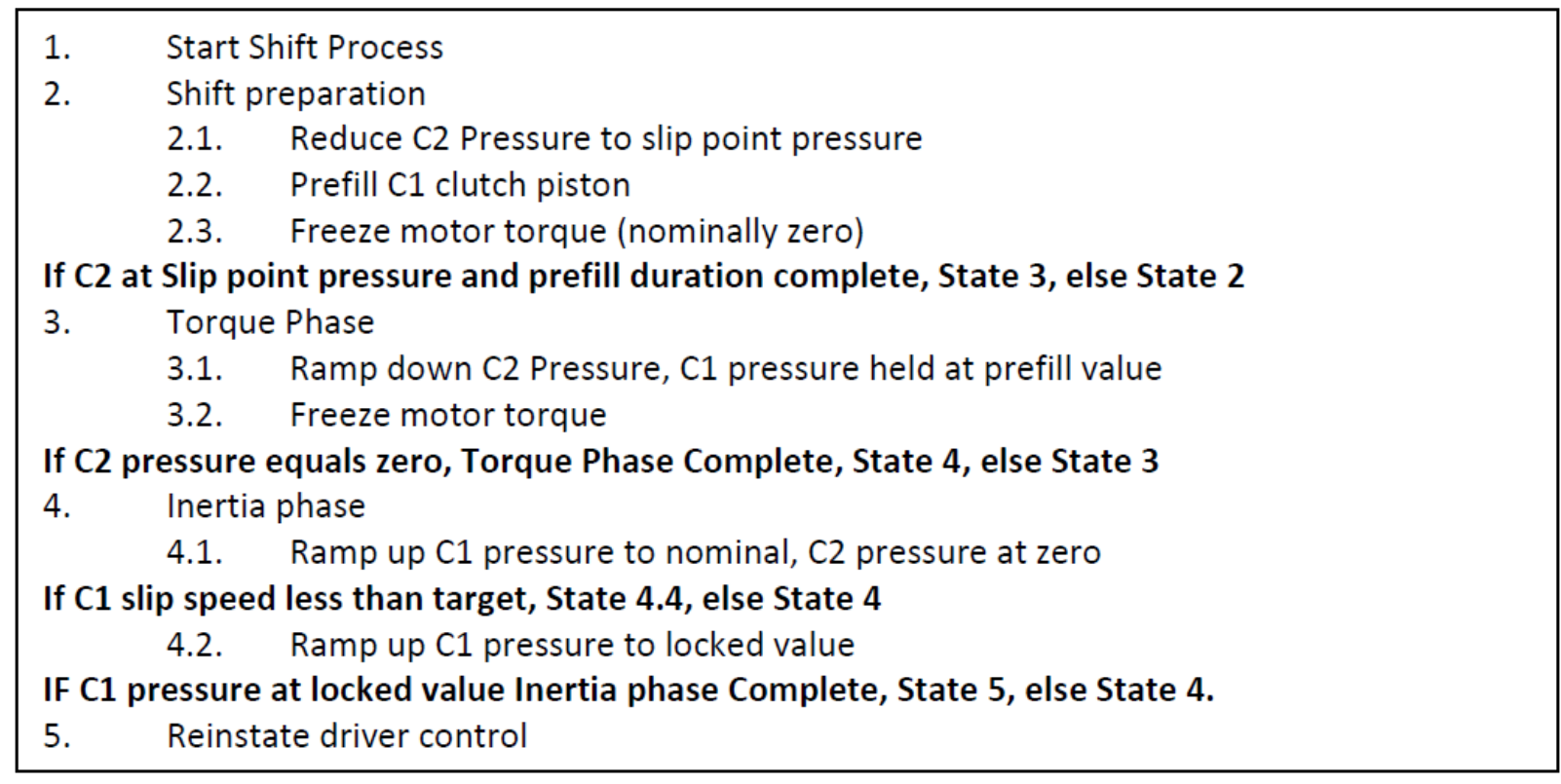

Figure 9: Control algorithm of Power-off Down-shift

\section{Experimental setup}

The experimental layout is presented in Figure 10 for reference. The powertrain system comprises of the front wheel drive assembly of a large passenger sedan. The wheels drive a set of flywheels that simulate the inertial load of a vehicle equivalent to $1500 \mathrm{~kg}$. The resistance torque is applied to the system using another axle that drives an eddy current dynamometer. The DCT block represents a DQ250 transmission that has been modified for two speed operation as discussed in Section 2. The system is controlled by custom software implemented on MicroAutoBox for the VCU/TCU. The motor is a brushless DC motor with a continuous power of $45 \mathrm{~kW}$ and peak of $125 \mathrm{~kW}$, it is controlled using the inverter drive which is integrated with the VCU. Sensors, denoted by 'S', represent the location of two wireless torque transducers of the strain gage type. A number of other sensors (not shown) collect motor speed, voltage, current and motor torque, and transmission output speed. 

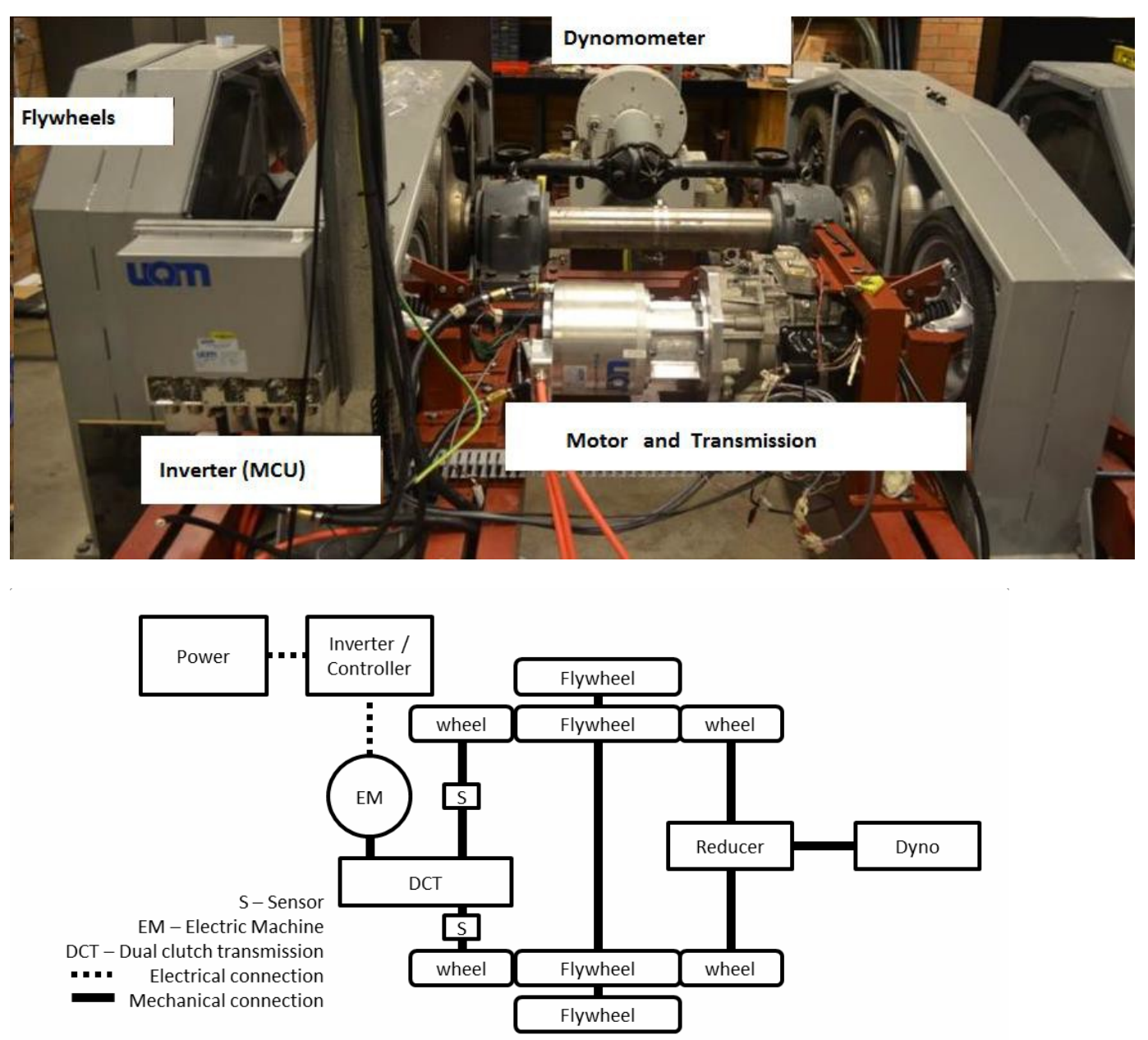

Figure 10: Experimental laboratory setup.

\section{Shift quality criteria}

Shifting quality is the extent under which the transmission can complete shifting process quickly and smoothly. Good shifting quality requires gearshift to be short with minimal transients and shock. For multi-body powertrain systems, such as dual clutch transmissions, it is not possible to eliminate jerk during the shifting, but to reduce it [27-29]. Two of the most commonly used quality criteria shifting time and jerk are used in this paper for analysis.

\subsection{Shifting Time}

The duration of gearshift can be defined using a number of alternative variations. The two extremes include from the point when gear change is requested to the completion of shifting as the longest possible shift time, or the duration of only the inertia phase of shifting as the shortest possible evaluation of shift time. Whilst the former considers all events in the shift process, the later 
considers only the portion of shifting that is observable by the driver. In this paper the duration of gear shift is defined from portion of the gear shift that is observable by the driver, selected as it has the most direct impact on perceived shift quality.

\subsection{Vehicle Jerk}

Jerk is the change rate of vehicle longitudinal acceleration. If the jerk is too large, indicates that passengers will observe a significant longitudinal shock. Its mathematical expression is as follows:

$$
j=\frac{\mathrm{d}^{2} \mathrm{u}}{\mathrm{dt}^{2}}=\frac{1}{\delta \mathrm{m}} \frac{\mathrm{i}_{\mathrm{g}} \mathrm{i}_{0} \eta_{\mathrm{t}}}{\mathrm{r}_{\mathrm{d}}} \frac{\mathrm{dT}_{\mathrm{c}}}{\mathrm{dt}}
$$

Where $u$ is speed, $\delta$ is vehicle gyrating mass conversion factor, $m$ is vehicle mass, $i_{g}$ is gear ratio and $i_{0}$ is final ratio, $\eta_{t}$ is transmission efficiency, $r_{d}$ is wheel rolling radius, $T_{c}$ is clutch friction torque. Equation 18 shows that jerk is proportional to the change rate of clutch torque. The faster the torque change, the shorter the clutch shifting time will be, and the larger the jerk of driven system can be. However, as we cannot accurately measure the clutch torque directly with the current experimental arrangement, therefore vehicle jerk is determined by combining the half shaft torques, dividing by the flywheels' inertia, and wheel rolling radius to generate the effective linear acceleration. The vehicle acceleration is numerically differentiated with respect to time.

$a=R_{t} \frac{T_{H S 1}+T_{H S 2}}{I_{V}}$

where $a$ is longitudinal acceleration and THS1 and THS2 are the half shaft torques.

Vehicle jerk is a mode of evaluating the quality of shifting observed by a passenger. The criterion for preferred maximum vehicle jerk during power-on shifting varies between regions. For example, Germany recommends $|J|<10 \mathrm{~m} / \mathrm{s}^{3}$, whilst in China it is $|\mathrm{J}|<17.64 \mathrm{~m} / \mathrm{s}^{3}[27]$.

\section{Simulations and experiments}

The first series of results presented in Figures 11 and 12 are for the simulated power-on and poweroff up and down shifts in the EV powertrain. Power-on gear shifts are undertaken at $30 \%$ of full throttle. The results present (a) power-on upshift, (b) power-on downshift, (c) power-off upshift and (d) power-off downshift. These results present high quality shift results for power-on shifting in 
particular. Notice, predominantly in Figure $11(\mathrm{a})$, but also in (b), the extended transient responses as the clutch locks up, indicated that the system is lightly damped, requiring high quality shift control.
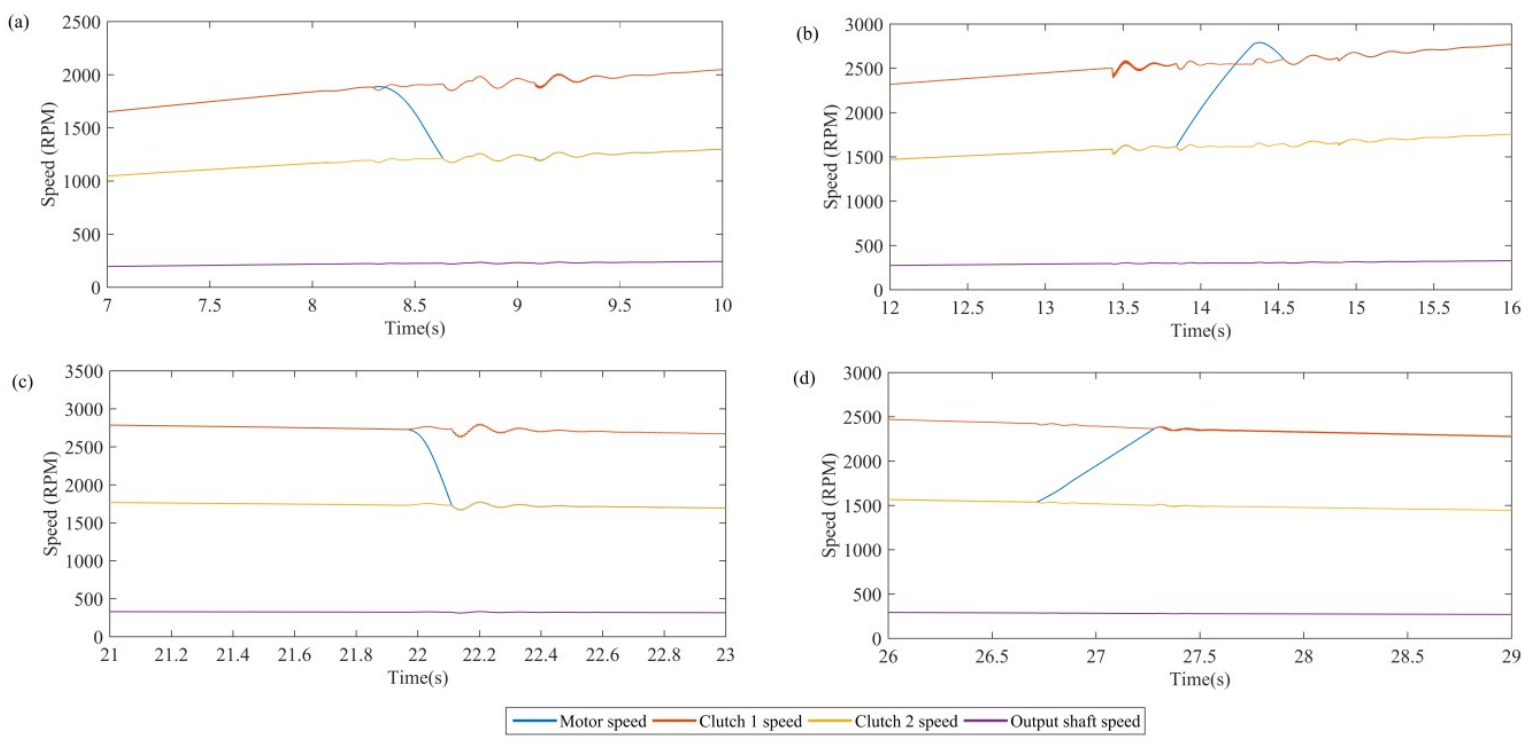

Figure 11: shift transient experimental results: (a) power-on upshift, (b) power-on downshift, (c) power-off upshift, and (d) power-off downshift

Figure 12 presents the vehicle acceleration and jerk results from the simulation study. In line with the requirements for filtering of experimental torque data, these results have been filtered using a low pass filter at $100 \mathrm{~Hz}$, this removes higher transient frequencies from the results but maintains the lower frequency responses that are present in the vehicle response. These are more likely to be observed by the driver as poor shift quality. The results show that both the power-on gear shifts, up and down, have peak jerk responses of close to the maximum desirable of $10 \mathrm{~m} / \mathrm{s}^{3}$. These occur during the inertia phase and lockup of the powertrain in the target gear. Figure 12 (a) demonstrates the torque hole present in these power-on shifts, at $1 \mathrm{~s}$ for the downshift and $0.8 \mathrm{~s}$ for the upshift.

For power-off shifting two separate cases discussed with respect to Figure 11 are represented below. As clutch 2 closes for the power-off upshift the shift is completed, and larger vehicle jerk is observed. But for the corresponding downshift as the motor accelerates over a longer duration shift quality is significantly improved. 
(a)
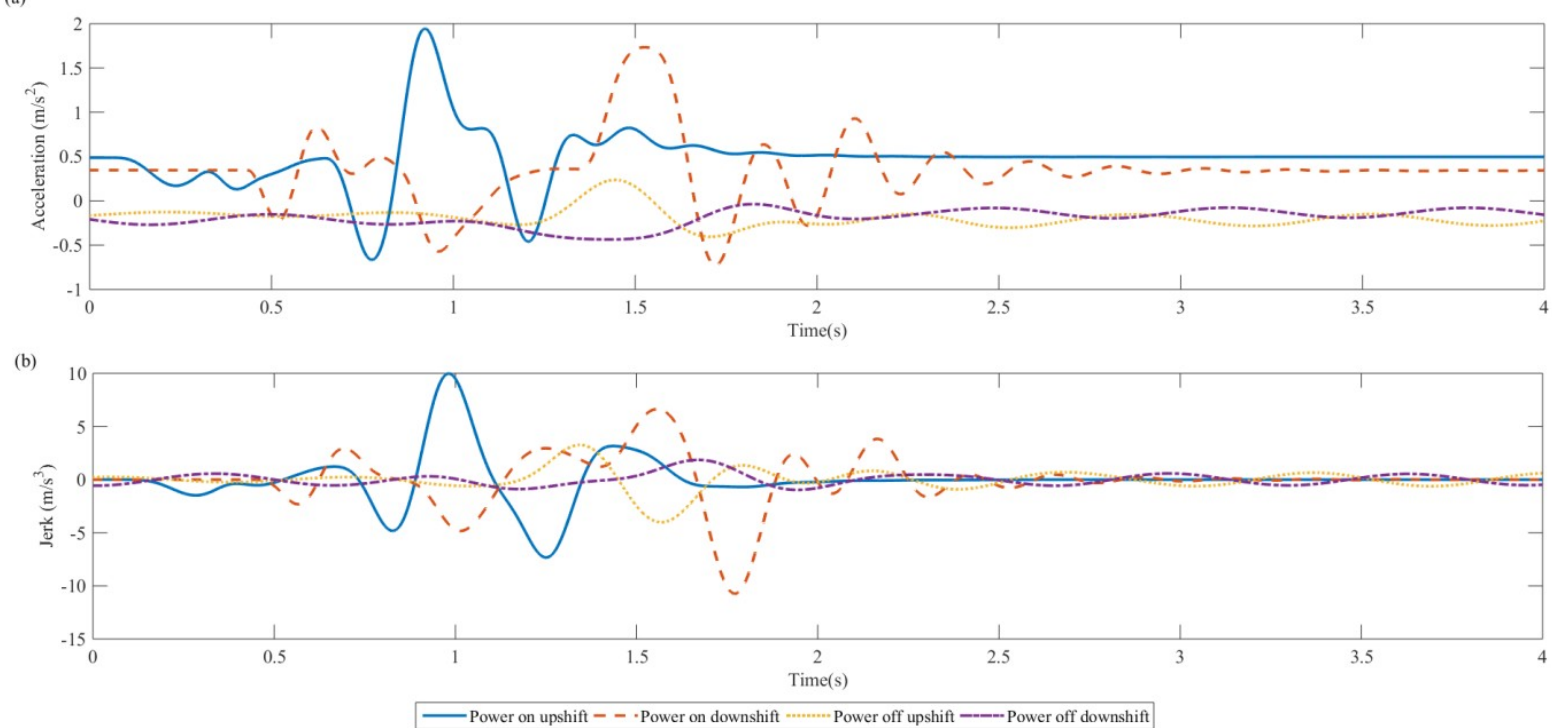

Figure 12: Shift transient responses (a) simulated vehicle acceleration, and (c) simulated vehicle jerk.

In experimental result the clutch 1 and clutch 2 speeds are calculated from the output shaft speed by multiplying by gear 1 and gear 2 overall ratios, respectively. Therefore the results represent an amplification of the output shaft speed $f$ the transmission. There is clear demonstration of the power-on shifting capabilities of the transmission for both up and down shifts in Figure 13 (a) and (b). The results show transient responses consistent with the simulated outcomes that demonstrate the lightly damped nature of the system and its subsequent need for high quality shift performance. For the power-on downshift in particular the motor over running of clutch 1 is more pronounced than in simulations, this outcome is consistent with the larger torque hole shown in Figure 14.

For power-off gear shifts in Figure 13 (c) and (d) the primary speed change occurs as the ongoing clutch is locked together consequently significant transient occur as the dynamic clutch torque reaches its peak. This presents as a limitation to this control strategy, as it is presumed by the authors that as the drag torque is significantly smaller in the electric drive than in a conventional engine. Any residual pressure in the clutch will maintain the sticking condition, thereby delaying the shift process. This is not captured in the simulated results as a consequence of model simplifications, 
notably the lack of hysteresis in the clutch assembly. As a consequence, any sticking behaviour in the clutch prevents a more desirable shift response where lower clutch torque preform an extended shift as shown in figure $11(\mathrm{~d})$.

Experimental powers off shift results also demonstrate a noticeable backlash component in Figure 13 (c) in particular. This verifies that whist the assumption of no backlash is correct for the power-on shifting results; there is a presence of this phenomenon in power-off shift results.
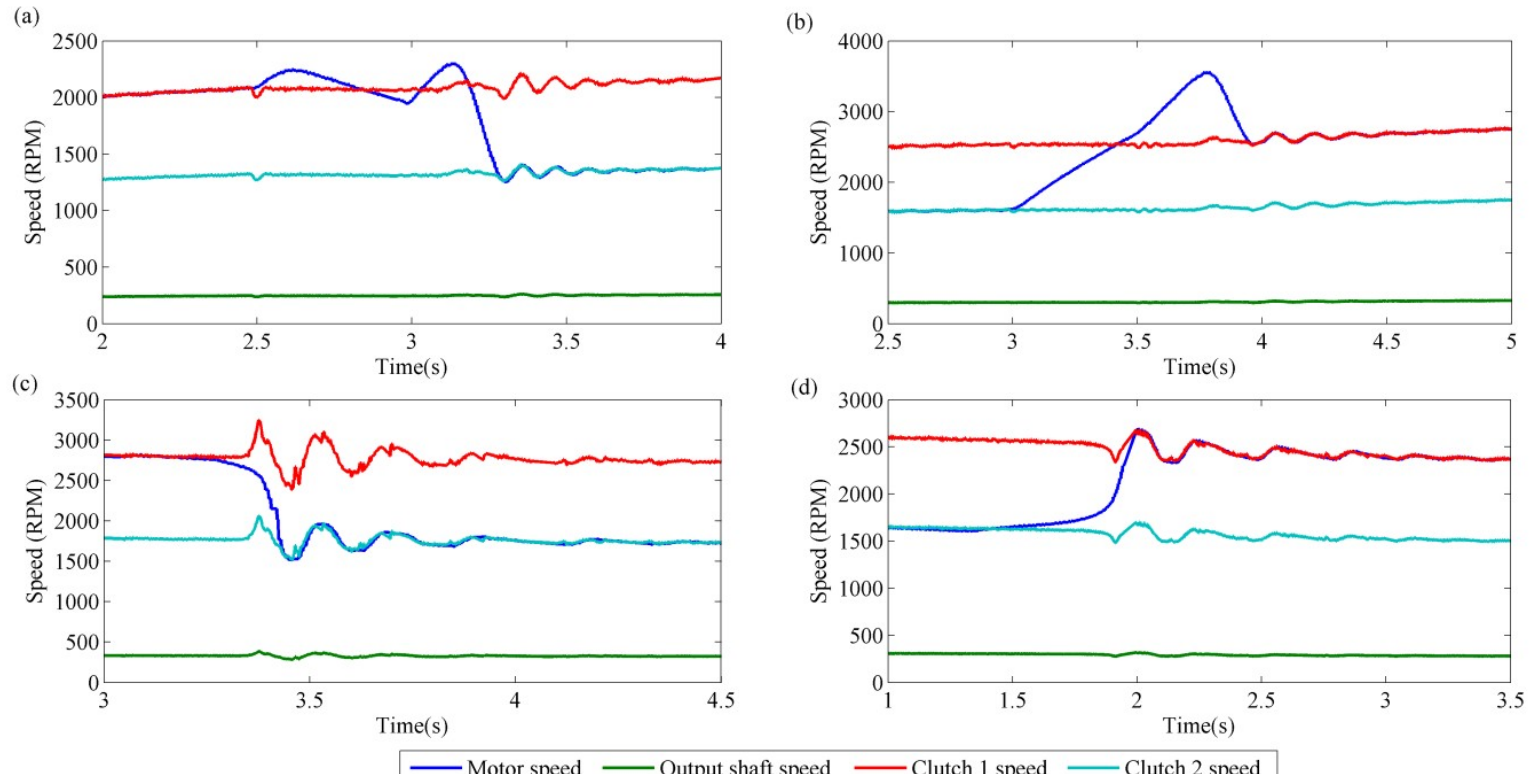

Figure 13: shift transient experimental results: (a) power-on upshift, (b) power-on downshift, (c) power-off upshift, and (d) power-off downshift

Experimental results for vehicle jerk are shown below in Figure 14. The results in figure 14 (a) show the total torque from output shaft sensors. Equations 20 and 21 are applied to the data to generate the plots in Figure 14 () and (c). The non-contact torque sensors used in this application are essentially antennae that trap any RF noise in the test bed, and as a consequence, electrical noise from the IGBT inverter produces considerable interference in the sensor. To extract valuable signals form the torque sensors it is therefore required to utilise a low pass filter, set to $100 \mathrm{~Hz}$, to reduce the high frequency noise from the motor controller (inverter). This limits the frequency range of the data, but still produces valid responses in the lower frequency range. The vehicle acceleration 
results in Figure 14 (b) demonstrate a more obvious torque hole during the shift transients when compared to the simulation results previously presented. These results do demonstrate, however, lower vehicle jerk transients than was achieved in the simulated results for power-on shifting. During power-off gear shifts the results do not match as well with simulations. This is a result of the engaging clutch forcing the shift as detailed previously with respect to Figure 14.
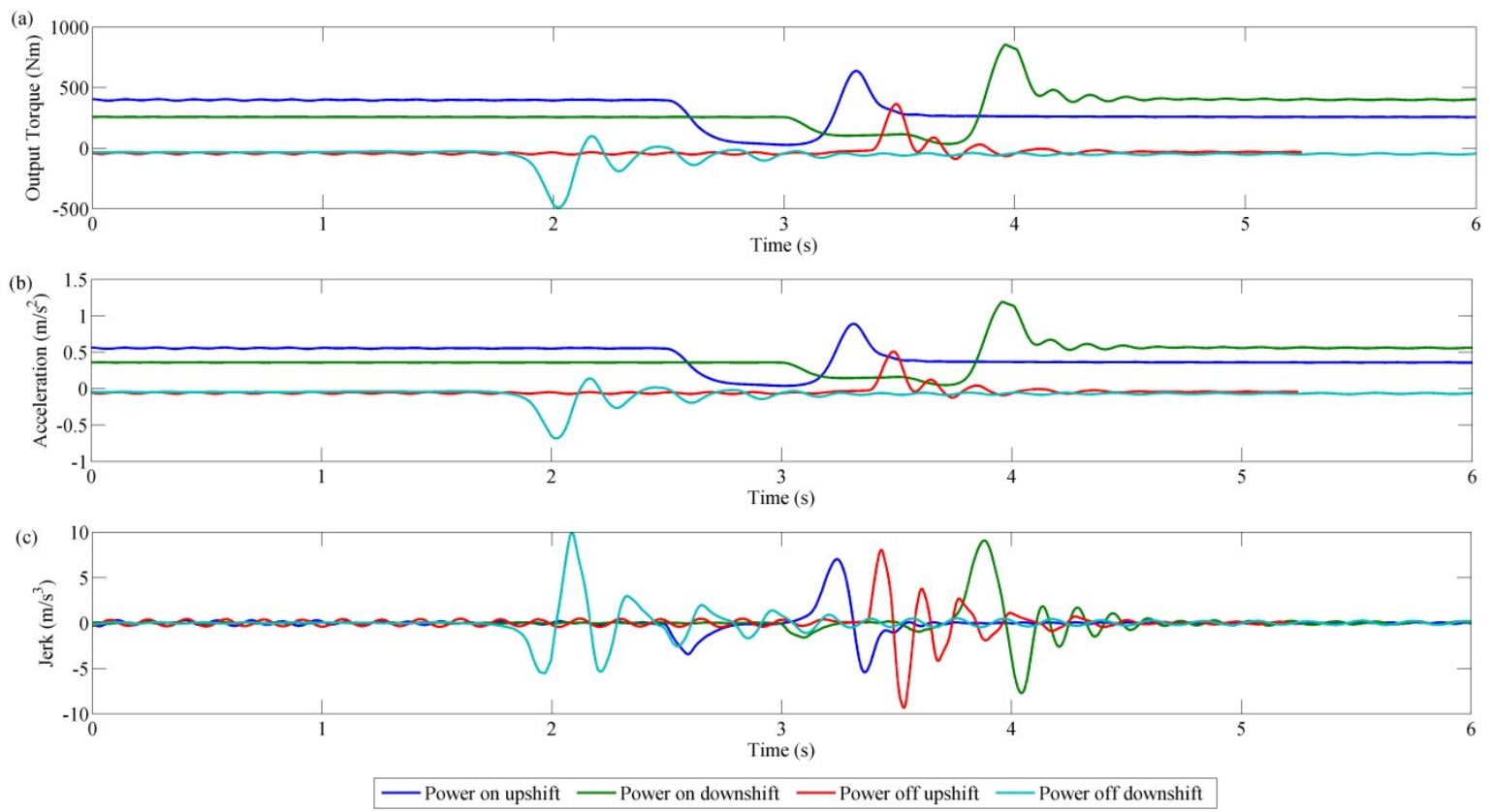

Figure 14: Shift transient responses (a) measured output shaft torque, (b) calculated vehicle acceleration, and (c) calculated vehicle jerk.

Table 1 presents the summarised duration for simulated and experimental shifts. The largest discrepancy in these results is for the power-on upshift. In simulated results in Figure 11 (a) the torque phase occurs largely before slip is initiated in the clutch and minimal slip occurs during torque handover. However, in the experimental results torque handover occurs with noticeable slip in Clutch 1. This results in the longer observable shift duration, and the more notable torque hole in Figure 14.

Table 1: Summary of shift durations from theoretical and experimental results. 


\begin{tabular}{|l|r|r|}
\hline & Simulated duration (ms) & Experimental duration (ms) \\
\hline Power-on upshift & 500 & 850 \\
\hline Power-on downshift & 900 & 1000 \\
\hline Power-off upshift & 200 & 300 \\
\hline Power-off downshift & 600 & 700 \\
\hline
\end{tabular}

\section{Conclusions and recommendations}

The purpose of this paper is to develop an extensive mathematical model of a two speed dual clutch transmission powertrain for electric vehicles, propose control strategies for all four primary shift categories, and demonstration of these control strategies through simulations with thorough experimental verification. To achieve this outcome the development of extensive shift control algorithms was presented covering power-on and power-off shifting for both up and down shifts for powertrain shift control. These shift control strategies were then applied to a theoretical model before being demonstrated experimentally using a full scale powertrain test rig. This demonstrates that the multi-body model is a reasonable representation of the physical model and can be utilised for analysis of various shift control problems.

The application of both power-on and power-off shift control strategies to electric vehicles have an important role in establishing multi speed electric vehicle applications with similar functionality to conventional vehicles. How these shift strategies should be applied to new energy vehicle technologies is established with torque based methods. Shift transients benefit significantly from smaller rotor inertia and minimal need for flywheels. Whilst this greatly reduces the shift duration for multispeed electric vehicles, the fact that these systems are comparatively lightly damped relative to conventional vehicle increases transient responses post gear shift. Results achieved both experimentally and through simulation demonstrated that it is possible to achieve short high quality gear shifts using torque based control techniques.

\section{Acknowledgements}


assistance in developing the prototype transmission. Financial support from the AutoCRC and the Australian Research Council (DP150102751) is gratefully acknowledged. Dr Bo Zhu would also like to thank Beijing Electric Vehicles Co for their ongoing support.

\section{References}

[1] Ren, Q., Crolla, D. a., and Morris, a. (2009). Effect of transmission design on Electric Vehicle (EV) performance. 5th IEEE Vehicle Power and Propulsion Conference, VPPC'09, 4(3), 1260-1265. doi:10.1109/VPPC.2009.5289707

[2] Walker, P. D., Abdul Rahman, S., Zhu, B., Zhang, N., (2013) Modelling, Simulations, and Optimisation of Electric Vehicles for Analysis of Transmission Ratio Selection Advances in Mechanical Engineering, 5:340435.

[3] Son, H., Yoon, Y. S., Kim, K. S., Kim, S. J., and Song, C. (2015) "Economic Hybrid Transmission System using Clutchless Geared Manual Transmission" In the 28th Electric Vehicle Symposium and Exhibition, 3-6 May, Goyang Korea.

[4] Naunheimer, H., Bertsche, B., Ryborz, J., Novak, W., Kuchle, A. (2010). Automotive Transmissions : Fundamentals, Selection, Design and Application (2nd ed.). Springer Berlin Heidelberg.

[5] Tseng, C. Y., and Yu, C. H. (2015). Advanced shifting control of synchronizer mechanisms for clutchless automatic manual transmission in an electric vehicle. Mechanism and Machine Theory, 84, 37-56.

[6] Sorniotti, A., Holdstock, T., Everitt, M., Fracchia, M., Viotto, F., Cavallino, C., and Bertolotto, S. (2013). A novel clutchless multiple-speed transmission for electric axles. International Journal of Powertrains, 2(2-3):103-131.

[7] Rahimi Mousavi, M.S.; Boulet, B., (2014) "Modeling, simulation and control of a seamless twospeed automated transmission for electric vehicles," American Control Conference (ACC), 2014 , pp.3826,3831, 4-6 June 2014. doi: 10.1109/ACC.2014.6859049

[8] Walker, P. D., Zhang, N. , and Tamba, R., (2011) Control of gear shifts in dual clutch transmission powertrains, Mechanical Systems and Signal Processing, 25(6):1923-1936.

[9] Crowther, A. R., Singh, R., Zhang, N., and Chapman, C., Impulsive response of an automated transmission system with multiple clearances: formulation, simulation, and experiment, J. Sound and Vibration. 306 (2007) 444-466.

[10] Gao, B., Liang, Q., Xiang, Y., Guo, L., and Chen, H. (2015). Gear ratio optimization and shift control of 2-speed I-AMT in electric vehicle. Mechanical Systems and Signal Processing, 50, 615-631.

[11] Zhou, X., Walker, P. D., Zhang, N., Zhu, B., (2013) “Performance Improvement of a Two Speed EV through Combined Gear Ratio and Shift Schedule Optimization", SAE Technical Paper 2013-01-1477.

[12] Di Nicola, F., Sorniotti, A., Holdstock, T., Viotto, F., and Bertolotto, S. (2012). Optimization of a Multiple-Speed Transmission for Downsizing the Motor of a Fully Electric Vehicle. SAE Int. J. Alt. Power., 1(1), 134-143. doi:10.4271/2012-01-0630 
[13] Roser, H. M., Walker, P. D. \& Zhang, N., (2013) “Robustness Analysis of Two-Speed Electric Vehicles", ASME 2013 International Mechanical Engineering Congress and Exposition, San Diego, California, USA, November 15-21, 2013, ASME Publishing, Paper No. IMECE2013-64139.

[14] Zhu, X., Zhang, H., Xi, J., Wang, J., and Fang, Z. (2014). Robust speed synchronization control for clutchless automated manual transmission systems in electric vehicles. Proceedings of the Institution of Mechanical Engineers, Part D: Journal of Automobile Engineering, 229 (4), pp 424-436.

[15] Sheng, K., Williams, B.W., Finney, S.J., (2000) "A review of IGBT models," IEEE Transactions on Power Electronics, 15(6):1250-1266. doi: 10.1109/63.892840

[16] Walker, P. D., Zhu, B., and Zhang, N., (2014) “Nonlinear Modeling and Analysis of Direct Acting Solenoid Valves for Clutch Control", Journal of Dynamic Systems, Measurement, and Control, 136(5):051023.

[17] Walker, P. D., Zhang, N., Zhan, W., and Zhu, B., (2012) Modelling and simulation of gear synchronisation and shifting in dual-clutch transmission equipped powertrains, Proc Instn Mech Engrs Part C: Journal of Mechanical Engineering Science, 227(2):276-287. doi:10.1177/0954406212449550.

[18] Goetz, M., Levesley, M., and Crolla, D., (2005) Dynamics and Control of Gearshifts on Twin-Clutch Transmission, Proc Instn Mech Engrs Part D: J Automobile Engineering. 219:951-963.

[19] Oh, J. J., Choi, S. B., and Kim, J., "Driveline modelling and estimation of individual clutch torque during gear shifts for dual clutch transmission" Mechatronics, 2014, 25(5):449-463.

[20] Goetz M., Integrated powertrain control for twin clutch transmissions, Ph. D. University of Leeds, 2005.

[21] Zhang, Y., Chen, X., Zhang, X., Jiang, H., Tobler, W., (2005) Dynamic modelling and simulation of a dual- clutch automated lay-shaft transmission, Journal of Mechanical Design, 127(3): 302-307.

[22] Kulkarni, M., Shim, T., Zhang, Y., (2007), Shift dynamics and control of dual-clutch transmissions, Mechanism and Machine Theory, 42: 168-182

[23] Song, X., Liu, J., Smedley, D., (2005), Simulation study of dual clutch transmission for medium duty truck application, SAE Technical Paper: 2005-01-3590, 2005.

[24] Wu, M., Lu, T., Ni, C., Zhang, J., (2010) Research on feedback linearization control of dual-clutch for dual clutch transmission, Mechanical Science and Technology for Aerospace Engineering, 29(10), 1285-1290.

[25] Liu, Z., Dong, X., Qin, D., Liu, Y., (2010) Analysis and control on shift quality of dual clutch transmission, Journal of Chongqing University, 33(5): 29-34.

[26] Lu Z, Chang X, Feng W, (2010) Up-shift control in wet double clutch transmission, Transactions of the Chinese Society of Automotive Engineers, 25(6): 132-136.

[27] Lu, Z., (2010) "Research on the Control Technology of Double Clutch Transmission with Two Gears Based on Pure Electric Car", PHD Thesis, Jilin University.

[28] Xie, F., Song, C., Liu, M., Zhang, Y., Lu Y.; (2008) Research on Co-simulation Platform Based on AMESim and Simulink for Dual State CVT; Automotive Technology; Vol. 8.

[29] Wang, P.,Wang, Q., Hu, A.,Yu, Y., (2008) Analysis of regenerative brake system of hybrid bus based on Simulink-AMESim co-simulation; Journal of Jilin University(Engineering and Technology Edition) Vol.38 Sup. Feb. 


\section{Appendix A}

Table A1: System parameters for powertrain model

\begin{tabular}{llllll}
\hline Symbol & Name & value & Symbol & Name & Value \\
\hline $\mathrm{J}_{1}$ & Motor & $0.065 \mathrm{kgm}^{2}$ & $\mathrm{~K}_{7}$ & Tyre stiffness & $22000 \mathrm{Nm} / \mathrm{rad}$ \\
$\mathrm{J}_{2}$ & Clutch drum & $0.3 \mathrm{kgm}^{2}$ & $\mathrm{~K}_{8}$ & Half shaft & $9390 \mathrm{Nm} / \mathrm{rad}$ \\
$\mathrm{J}_{3}$ & Clutch one & $0.0072 \mathrm{kgm}^{2}$ & $\mathrm{~K}_{9}$ & Tyre stiffness & $22000 \mathrm{Nm} / \mathrm{rad}$ \\
$\mathrm{J}_{4 \mathrm{a}}$ & Gear 1 & $0.015 \mathrm{kgm}^{2}$ & $\mathrm{C}_{1}$ & Tyre damping & $50 \mathrm{Nms} / \mathrm{rad}$ \\
$\mathrm{J}_{4 \mathrm{~b}}$ & Pinion 1 & $0.0075 \mathrm{kgm}^{2}$ & $\mathrm{C}_{2}$ & Tyre damping & $50 \mathrm{Nms} / \mathrm{rad}$ \\
$\mathrm{J}_{5}$ & Clutch two & $0.0125 \mathrm{kgm}^{2}$ & $\mathrm{~g}_{1}$ & Gear 1 & 2.08 \\
$\mathrm{~J}_{6 \mathrm{a}}$ & Gear 2 & $0.0094 \mathrm{kgm}^{2}$ & $\mathrm{~g}_{2}$ & Gear 2 & 1.32 \\
$\mathrm{~J}_{6 \mathrm{~b}}$ & Pinion 2 & $0.0063 \mathrm{kgm}^{2}$ & $\mathrm{~g}_{3}$ & Final drive 1 & 4.06 \\
$\mathrm{~J}_{7 \mathrm{a}}$ & Final drive 1 & $0.003 \mathrm{kgm}^{2}$ & $\mathrm{~g}_{4}$ & Final drive 2 & 4.06 \\
$\mathrm{~J}_{7 b}$ & Final drive 2 & $1.16 \mathrm{kgm}^{2}$ & $\mathrm{C}_{\mathrm{D}}$ & Drag coefficient & 0.3 \\
$\mathrm{~J}_{7 \mathrm{c}}$ & Final drive 3 & $0.001 \mathrm{kgm}^{2}$ & $\mathrm{C}_{\mathrm{R}}$ & Rolling resistance & 0.015 \\
$\mathrm{~J}_{8}, \mathrm{~J}_{10}$ & Wheel Hubs & $0.75 \mathrm{kgm}^{2}$ & $\mathrm{R}_{\mathrm{M}}$ & Mean clutch radius & $87 \mathrm{~mm}$ \\
$\mathrm{~J}_{9}, \mathrm{~J}_{11}$ & Half Vehicle & $75.6 \mathrm{kgm}^{2}$ & $\mathrm{~m}_{\mathrm{V}}$ & Vehicle mass & $1462 \mathrm{~kg}$ \\
$\mathrm{~K}_{1}$ & Motor output & $1 \times 10^{5} \mathrm{Nm} / \mathrm{rad}$ & $\mathrm{n}$ & Number of friction & 4 \\
& & & & surfaces & \\
$\mathrm{K}_{2}$ & Primary shaft 1 & $1 \times 10^{5} \mathrm{Nm} / \mathrm{rad}$ & $\mathrm{r}_{\mathrm{T}}$ & Tyre radius & $0.3795 \mathrm{~m}$ \\
$\mathrm{~K}_{3}$ & Lay shaft 1 & $1 \times 10^{5} \mathrm{Nm} / \mathrm{rad}$ & $\rho$ & Air density & $1.127 \mathrm{kgm}$ \\
$\mathrm{K}_{4}$ & Primary shaft 2 & $1 \times 10^{5} \mathrm{Nm} / \mathrm{rad}$ & $\beta$ & Road incline & $0^{\circ}$ \\
$\mathrm{K}_{5}$ & Lay shaft 2 & $1 \times 10^{5} \mathrm{Nm} / \mathrm{rad}$ & $\mu_{\mathrm{D}}$ & Dynamic friction & 0.12 \\
& & & & coefficient & \\
$\mathrm{K}_{6}$ & Half shaft & $11100 \mathrm{Nm} / \mathrm{rad}$ & $\mu_{\mathrm{S}}$ & Static friction & 0.16 \\
& & & & coefficient & \\
\hline
\end{tabular}


